for them at a rate of around $£ 250$ per week. No mention is made of the dialysis of the solitary parent and the care of children involved if this ceases.

The third fault is an ethical one, that if a treatment is available (and we have plenty of evidence that the public at large want to support this sort of treatment in machine and kidney donation), then the decision should not be in the hands of administrators or social scientists or even the Department of Health and Social Security, but be put very firmly before the relatives of the patients and the public. Regular dialysis was helped in Britain by public pressure, and if the social policy makers concentrated their efforts in getting the public to increase the falling $4.9 \%$ of the gross national produc directed towards health the need for selection would go and we could concentrate on efficiency.

No mention is made of the responsibility of society to care for patients, whatever their income or potential for productivity. Part of our social concern in this country is to continue and to be seen to care for those who can no longer add to its financial wealth. If this is not the case then such cost-benefit analyses should be directed towards the geriatric population and those with severe deformities.

The authors mention nothing of the advantages that large-scale dialysis programmes have brought to research in the prevention of renal disease, bone disease, and hypertension. Finally, the weakest part of the article is its exclusion of transplantation. We now have as many patients transplanted, living active and produotive lives, as we have patients on home dialysis. A unit in our own region has reached the situation where the dialysis unit's work load has been reduced in the past two years by one-half because of the activity of successful transplantation.

Costly compassion never was approved of by those who "held the bag," but if you stop caring with the skills that you have, true poventy will have begun.-We are, etc.,

VICTOR PARSONS SUSAN A. SNOWDEN

Dulwich Hospital,
London S.E.22

\section{Medical Education and the Pharmaceutical} Industry

SIR,-The Department of Health has requested members of the pharmaceutical industry to reduce their promotional expenditure from $13.8 \%$ to $10 \%$ of turnover. The industry has a well-founded and creditable reputation for giving support to educational aotivities, including the indirect support of reputable and valuable medical journals through the placement of advertising material. Naturally each company will wish to decide for itself where economies are to be made, but I plead that they be selective and bear in mind the advantages to the whole profession of continuing to advertise in journals of true educational value.-I am, etc.,

H. W. K. ACHESON
Potentiation of Warfarin by Co-trimoxazole

SIR,-Drs. D. B. Barnett and B. W. Hancock (15 March, p. 608) describe a patient resistant to anticoagulant treatment with warfarin. During the warfarin treatment the patient received co-trimoxazole for nine days, which caused a considerable increase in plasma warfarin level and a decrease in prothrombin index. The authors suggest that co-trimoxazole inhibits warfarin metabolism.

This interesting observation seems to confirm our finding of co-trimoxazole as an inhibitor of drug metabolism in man. In six patients receiving co-trimoxazole we found an increase in diphenylhydantoin (DPH) half life from $12 \cdot 8 \pm 4 \cdot 3$ hours to $19 \cdot 2 \pm 3 \cdot 9$ hours and a decrease in metabolic clearance rate from $41 \cdot 3 \pm 13.4 \mathrm{ml} / \mathrm{min}$ to $30 \cdot 1 \pm 10 \cdot 1$ $\mathrm{ml} / \mathrm{min}(\mathbf{P}<0.001){ }^{1}$ We have further studied the influence on DPH metabolism of number of sulphonamides. In usual therapeutic doses sulphaphenazole, sulphadiazine, and sulphamethizole also inhibited the metabolism of DPH, while sulphadimethoxine, sulphamethoxipyridazine, and sulphamethoxidiazine did not affect the half life and metabolic clearance rate of DPH. ${ }^{2}$ The biotransformation of other drugs metabolized in the liver microsomal enzyme system, suah as tolbutamide and warfarin, has also been found to be inhibited by sulphaphenazole, sulphamethizo'e, and sul phadiazine..$^{3-6}$

It is well known that sulphonamides increase the effect of coumarin anticoagulants, and this effect is generally thought to be explained by a depression of the intestinal bacterial flora producing vitamin K. However, the data of Drs. Barnett and Hancock and our own previous studies suggest that inhibition of coumarin metabolism caused by some sulphonamides might be the primary explanation of the hypoprothrombinaemic effect of these clinically important drug interactions.-We are, etc.,

J. MøLHOLM HANSEN K. SIERSBEK-NIELSEN L. SKOVSTED

J. P. KAMPMANN B. LUMHOLTZ

Medical Department F

Medical Department E, Frederiksberg Hospital,

1 Skovsted, L., et al., Drug Interactions, ed. P. I Morselli, S. Garattini, and S. N. Cohen, p. 81. New York, Raven Press, 1974.

2 Hansen, J. M., et al., Sven:ka Epilepsia, 1974, Suppl. 2, p. 23.

Christensen, L. K., Hansen, J. M., and Kristensen, M., Lancet, 1963, 2, 1298. . Acto Distensen, M., and Christensen, L. K., Acta Diabetologica Latina, 1969, 6, Suppl. 1, p. 116.
Siersbæk-Nielsen, K., et al., Clinical Pharmacology and Therapeutics, 1973, 14. 148 . Lumholtz, B., et al., Clinical Pharmacology and
Therapeutics. In press.

SIR,-We were interested to note the raised plasma warfarin level accompanied by inoreased prothrombin time in a patient who was also receiving co-trimoxazole, reported by Drs. D. B. Barnett and B. W. Hancock (15 March, p. 608). We have seen a potentiation of the action of warfarin probably due to this combination in seven patients. In two of these who were studied more fully, however, a fall in total serum warfarin (warfarin plus metabolites) was observed. This would be consistent with the displacement by sulphamethoxazole of some of the protein-bound warfarin, thus increasing both its intrinsic action and its rate of metabolism and excretion.

In-vitro studies, however, using therapeutic concentrations of the drugs, showed an increase of free warfarin from $20.6 \%$ to $23.4 \%$. We felt that such a small increase was unlikely to account for the increased hypoprothrombinaemic effect. The suggestion by the above authors that cotrimoxazole inhibits the metabolism of warfarin, presumably made after noting an increase in hydroxylated metabolites separated by chromatography, may therefore be the explanation.

Whatever the reason, the concurrent administration of co-trimoxazole to at least some patients already stabilized on warfarin may lead to an increase in prothrombin time.

Our full results will be published on completion.-We are, etc.

C. Hassall

C. L. FEETAM

R. H. LEACH

M. J. MEYNELL

Departments of Pharmacy and Haematology,
Queen Elizabeth Hospital, Birmingham

\section{Racial Differences in Leucocyte Count}

SIR,-We read with great interest the paper by Drs. Barbara J. Bain and J. M. England (8 February, p. 306) about sex difference in the neutrophil count. It raises the question: What is "normal range" in most biological investigations, especially when comparing populations from very different parts of the world? We would like to enlarge on a point which Drs. Bain and England mentionracial differences in leucocyte count. As they point out, Shaper and Lewis and others, ${ }^{1-4}$ particularly in East Africa, have shown that African patients, more often when living in a traditional manner, show a strong neutropenia.

We have observed the same phenomenon in West Africa. ${ }^{5}$ The entire adult populations of three rural communities of the Bamako region (Mali Republic) were examined in March 1973. A capillary puncture was performed by means of the Unopette system to reduce the errors of manipulation as much as possible. The total leucocyte count was made in a Nageotte glass cell by a single observer under field conditions. The differential count was made on the basis of 100 cells stained with May-Grünwald and Giemsa. The table compares our findings with those from other African populations and with Wintrobe's American norms. ${ }^{6}$

Seemingly leucopenia due to neutropenia is a constant feature in Africans. Over $5 \%$ of our subjects had a neutrophil count lower than $1 \times$ $10^{9} / 1\left(1000 / \mathrm{mm}^{3}\right) .^{5} \mathrm{~A}$ genetic origin for this phenomenon has not been established. ${ }^{7} 8 \mathrm{We}$ have discussed elsewhere ${ }^{5}$ some environmental factors, such as malaria infestation or leucokinetic patterns, the well-known "tropical hypereosinophilia" is commonly observed, especially in Malians. The highly prevalent helminthiases like schistosomiasis and onchocerciasis certainly play a causative role in eosinophilia. Nevertheless, its precise causes remain unknown. ${ }^{4}$ ? The low monocyte count common in African populations seems to confirm the positive correlation between neutrophil and monocyte counts seen by Drs. Bain and England.

This brief analysis could be developed in more detail, but our aim is simply to draw attention to the important geographical differences in leucocyte count. Since patients 